\title{
The factors that influence oral health- related quality of life in young adults
}

\author{
Ling Sun ${ }^{1}$, Hai Ming Wong ${ }^{1 *}$ (DD and Colman P. J. McGrath ${ }^{2}$
}

\begin{abstract}
Background: Young adulthood is a time when subjects transform their role from a dependent child to an independent social identity. This cross-sectional study aimed to analyze the sociodemographic and clinical factors that may influence the OHRQoL of 18-year-old young adults.

Methods: A representative sample was selected from Hong Kong. Periodontal status and caries were examined according to WHO criteria. Four orthodontic indices were used to assess malocclusion. The oral health impact profile (OHIP-14) was used to measure OHRQoL. Adjusted OR was calculated by ordinal logistic regression.

Results: A total of 300 eligible subjects (165 females, 135 males) were recruited. Females had more severe caries than males; however, gender was not a significant factor of OHRQoL. Household income affected OHRQoL more than parents' education did: household income had effects on physical pain, psychological discomfort, psychological disability, and the total OHIP; while parents' education had some effects on functional limitation, physical pain and psychological discomfort. As for clinical factors, unhealthy periodontal conditions were more prevalent than caries $(94.67 \%$ vs. 59.00\%); however, both of them showed no effect on OHRQoL. Malocclusion had a negative effect on OHRQoL; the most affected subscales were psychological discomfort and psychological disability.

Conclusion: In this study, family ecosocial factors and malocclusion had an effect on OHRQoL. Among the family ecosocial factors, it was household income that had the most effect on OHRQoL. Malocclusion mainly affected the subscales of psychological discomfort and psychological disability. Gender, periodontal status and caries had no effect on young adults' OHRQoL.
\end{abstract}

Keywords: Oral health-related quality of life, Periodontal status, Caries, Malocclusion, Sociodemographic factors, Young adults

\section{Background}

The concept of health-related quality of life emerged in the late 1960s, while the concept of oral health-related quality of life (OHRQoL) appeared in the early 1980s [1]. OHRQoL measures not only oral symptoms and functional limitations, but also their impacts on patients' psychosocial status. Psychosocial status is liable to change according to age; hence quality of life is a "dynamic construct" that is likely to change overtime [2].

During adolescence, subjects' physical and psychological statuses develop rapidly. Subjects become more aware of their appearance; their emotion is vulnerable

\footnotetext{
* Correspondence: wonghmg@hku.hk

${ }^{1}$ Paediatric Dentistry and Orthodontics, Faculty of Dentistry, The University of Hong Kong, 2/F, Prince Philip Dental Hospital, 34 Hospital Road, Sai Ying Pum, Hong Kong

Full list of author information is available at the end of the article
}

and changeable [3]. In adulthood, subjects' perceptions of inside and outside world are relatively stable [4]. Young adulthood is a time that bridges adolescence and adulthood, in which subjects transform their role from a dependent child to an independent social identity [5]. To date, only a few studies have been conducted on the factors that influence young adults' OHRQoL; a final conclusion has not been reached in this area [6-11].

This article is a cross-sectional study aimed to analyze the sociodemographic and clinical factors that may influence young adults' OHRQoL. The sample of this study was randomly selected from 18-year-old students in Hong Kong.

(c) The Author(s). 2018 Open Access This article is distributed under the terms of the Creative Commons Attribution 4.0 International License (http://creativecommons.org/licenses/by/4.0/), which permits unrestricted use, distribution, and reproduction in any medium, provided you give appropriate credit to the original author(s) and the source, provide a link to the Creative Commons license, and indicate if changes were made. The Creative Commons Public Domain Dedication waiver (http://creativecommons.org/publicdomain/zero/1.0/) applies to the data made available in this article, unless otherwise stated. 


\section{Methods}

\section{Measurement instruments}

The short form of oral health impact profile (OHIP-14) was used to assess OHRQoL. The following 7 dimensions are measured: functional limitation, physical pain, psychological discomfort, physical disability, psychological disability, social disability, and handicap. For each question subjects are asked how frequently they had experienced the impact in the preceding 12 months. The responses followed a Likert-type scale coded as 'never' $=0$; 'hardly ever' $=1$; 'occasionally' $=2$; 'fairly often' $=3$; and 'very often' $=4$. The total score can be calculated as the sum of the item scores, generating scores from 0 to 56 for OHIP-14, with higher scores indicating worse OHRQoL [12].

Community Periodontal Index (CPI) and the Decayed, Missing and Filled Teeth (DMFT) were used to measure periodontal and caries conditions according to the criteria of WHO [13]. Significant Caries Index (SiC index) was also used to classify caries. The one third of the population with the highest caries score is selected and the mean DMFT for this subgroup constitutes the $\mathrm{SiC}$ Index value [14].

Index of Orthodontic Treatment Need (IOTN), Dental Aesthetic Index (DAI), Index of Complexity, Outcome and Need (ICON), and Peer Assessment Rating (PAR) were used to assess orthodontic treatment need and complexity [15-20].

IOTN includes Dental health component (DHC) and Aesthetic component (AC). DHC has 5 grades (no need to very great need) and the worst occlusal trait is recorded to allocate the grade. AC is comprised of 10 front view photographs, which represents 10 scales of dental attractiveness. The IOTN (DHC) or IOTN (AC) grading can be further categorized into three orthodontic treatment groups (DHC 1-2 or AC 1-4, no need; DHC 3 or AC 5-7, borderline need; DHC 4-5 or AC 8-10, definite need) [21, 22].

The index of DAI is calculated by multiplying the measurements of 10 occlusal traits by their weights; the addition of their products and the addition of a constant number, 13, is the final DAI score. It can be categorized into 4 scales of orthodontic severity and treatment need ( $\leq$ 25 , normal or minor malocclusion-no treatment need or slight need; 26-30, definite malocclusion-treatment selective; 31-35: severe malocclusion-treatment highly desirable; $\geq 36$ : very severe (handicapping) malocclusion-treatment mandatory) [18].

ICON is used to evaluate treatment need, treatment outcome and complexity [19]. Its aesthetic score is assessed using IOTN (AC). Five occlusal trait scores are multiplied by their respective weights and summed to calculate the ICON score. The ICON score can be scaled into 2 categories for treatment need ( $\leq 43 \mathrm{No}$; $>43 \mathrm{Yes}$ ), and 5 categories for orthodontic complexity $(<29$ easy;
29-50, mild; 51-63 moderate; 64-77 difficult; > 77 very difficult).

PAR is an estimate of how far a case deviates from normal. The concept is to assign a score to 11 components of occlusal traits that make up a malocclusion. The individual scores are summed together to obtain an overall total, representing the degree a case deviates from normal occlusion. Generally a measure of 10 or less indicates an acceptable alignment and occlusion, and 5 or less suggests an almost ideal occlusion [17].

\section{Study population and data collection}

Cluster randomized trial was used in this study. The sampling frame was all local secondary schools in Hong Kong (by law all children are required to attend secondary school). A random sample of 45 schools (approximately $10 \%$ of all local secondary schools) was selected from 18 districts in Hong Kong, SAR. Students born between April 1st and May 31st, 1997 were invited to participate in the oral health survey conducted by Faculty of Dentistry, the University of Hong Kong. The sample of this study was selected from the birth cohort of "children of 1997" [23].

This study was part of a longitudinal study that was planned to follow subjects from age 12 to 18 . Sample size was calculated based on a previous study [24-26]. The prevalence of orthodontic treatment need (ICON) was $80.3 \%$; the mean CPQ scores (SD) were respectively 20.1 (14.0) and 14.8 (15.0) for "with treatment need" group and "without treatment need" group; $\alpha=0.05$, and $1-\beta=0.8$. With a lost rate of $30 \%$ at each follow-up and the design effect for cluster sampling considered, the sample sizes at ages 12,15 , and 18 should be 237,166 , and 116 , respectively.

It should be noted that at age 18, not only subjects who were followed up from age 12 came to the survey again, but also some new subjects, who did not show up in the past surveys, were willing to participate in this 18-year-old survey. Therefore, this article is a cross-sectional analysis of all these 18-year-old subjects; the longitudinal analysis for the subjects who were followed up from age 12 to 18 was demonstrated in another article.

Students' oral health status was examined using an intra-oral disposable mouth mirror with a built-in LED light source. The same trained and calibrated examiner performed the oral examination according to the criteria of WHO [13]. Front-view dental photos were taken by extracting lips using oral retractors to assess IOTN (AC). Dental impressions were collected and the plaster models were sent to OrthoLab (Poland) to make digital models. Software O3DM (version3.8.5 (c) by OrthoLab, Poland) was used to analyse digital models by the same examiner. Reassessments were performed among 10\% 
randomly selected samples after 2 weeks of first assessment to test intra-examiner's reliability.

Systematic health information, dental treatment history, ecosocial factors including father's education, mother's education, and household income were collected from a self-completed questionnaire. OHRQoL was assessed by inviting participants to answer questions in OHIP-14. Subjects were excluded from the final analysis if they were systemically unhealthy, had orthodontic treatment history, or had oral diseases other than caries, periodontitis and malocclusion.

\section{Ethics, consent and permissions}

The ethical approval of this study was granted by the Institutional Review Board of the University of Hong Kong/ Hospital Authority Hong Kong West Cluster (UW 09453). A written consent from parents/primary caregivers and a verbal consent from students were obtained from all participants.

\section{Statistical methods}

Intra-examiner reliability was tested by kappa values for CPI, weighted kappa for IOTN (DHC) and IOTN (AC), and Intra-class correlation coefficient (ICC) for DMFT, DAI score, and ICON score.

Missing data only existed in some questions of family information. The problem was addressed as follows: the missing data were first checked in the data of age 15, and then in age 12; if the data were available at age 15 or age 12, they were used in this study. As such, only 6 subjects had missing data of one or two questions, which were filled with the mode of the corresponding data at age 18 .

Mann-Whitney $U$ test was used to analyze whether there was a difference of oral health status between females and males; independent samples t test was used to detect the difference of mean DMFT between females and males.

The effects of sociodemographic and clinical factors on OHRQoL were analyzed with parameters set as follows:

1. Dependent variables: for bivariate analysis, dependent variables were set as the subscale and the total scores of OHIP-14. For ordinal regression, if the data could be separated into four groups, the cut-offs were set as quartiles; if not, the cut-offs were set as medians; higher ranks represented poorer quality of life.

2. Independent variables: gender, father's education level (primary school graduate or below, secondary school, post-secondary or above), mother's education level (levels set as father's education), household income (total monthly income below HK\$10000, HK\$10001-HK\$20000, HK\$20001-
HK\$30000, HK\$30001-HK\$40000, HK\$40001 or above), periodontal status, caries experience, and orthodontic treatment need.

3. Bivariate analysis: comparison between two samples used the Mann-Whitney $U$ test, others used the Kruskal-Wallis $\mathrm{H}$ test.

4. Multivariate analysis: ordinal logistic regression was used to calculate adjusted odds ratios (OR). To avoid interaction effect, orthodontic treatment needs measured by different orthodontic indices were entered into regression separately.

\section{Results}

There were 383 subjects participating in the 18-year-old survey; of these, 300 (165 females, 135 males) were eligible for the final analysis. A total of 83 subjects were excluded from this study, of whom 33 were systematically unhealthy, and 50 were with orthodontic history or without oral impressions. Of the eligible subjects in this study, 204 (114 females and 90 males) participated in both 15-year-old and 18-year-old surveys; 188 (106 females and 82 males) participated in all three surveys.

Kappa value for CPI was 0.789; weighted kappa for IOTN (DHC) and IOTN (AC) were 0.918 and 0.790; ICC for DAI score, ICON score and DMFT were 0.821, 0.820 and 0.996 .

The oral health status of subjects is presented in Table 1. In this 18-year-old sample, the mean DMFT (SD) was 1.92 (2.373) and the $\mathrm{SiC}$ index value (SD) was 4.72 (2.021). Unhealthy periodontal conditions were more prevalent than caries $(94.67 \%$ vs. $59.00 \%)$. The prevalence of orthodontic treatment need was $46.33 \%$ measured by IOTN (DHC), $19.67 \%$ by IOTN (AC), $57.00 \%$ by DAI, $34.33 \%$ by ICON, and $46.00 \%$ by PAR . There was no difference of oral health status between females and males, except for caries. The prevalence of caries was not different between females and males; but the situation of caries was more severe in females than in males $(p=0.036$ and 0.003 for $\mathrm{SiC}$ index and DMFT, respectively).

The results of bivariate analysis are presented in Table 2. No difference of OHRQoL existed between females and males. The total OHIP score showed a gradient descent across the rates of both parents' education and household income; however, significant results only existed in household income. As for the subscales of OHIP-14, father's education showed effects on functional limitation and psychological discomfort; mother's education showed effects on physical pain; household income showed the most significant effects, which were presented on physical pain, psychological discomfort, and psychological disability.

In all subscales of OHIP-14, subjects with unhealthy periodontal conditions had a higher score than those 
Table 1 Profile of 18-year-old participants

\begin{tabular}{|c|c|c|c|c|c|c|c|}
\hline & \multicolumn{2}{|c|}{ Female } & \multicolumn{2}{|c|}{ Male } & \multicolumn{2}{|c|}{ Total } & \multirow[t]{2}{*}{$P$} \\
\hline & N & Percentage & N & Percentage & N & Percentage & \\
\hline \multicolumn{8}{|l|}{ IOTN (DHC) treatment need } \\
\hline No need & 89 & $53.94 \%$ & 72 & $53.33 \%$ & 161 & $53.67 \%$ & \multirow[t]{3}{*}{0.876} \\
\hline Borderline need & 35 & $21.21 \%$ & 28 & $20.74 \%$ & 63 & $21.00 \%$ & \\
\hline Definite need & 41 & $24.85 \%$ & 35 & $25.93 \%$ & 76 & $25.33 \%$ & \\
\hline \multicolumn{8}{|l|}{ IOTN (AC) treatment need } \\
\hline No need & 132 & $80.00 \%$ & 109 & $80.74 \%$ & 241 & $80.33 \%$ & \multirow[t]{3}{*}{0.952} \\
\hline Borderline need & 23 & $13.94 \%$ & 15 & $11.11 \%$ & 38 & $12.67 \%$ & \\
\hline Definite need & 10 & $6.06 \%$ & 11 & $8.15 \%$ & 21 & $7.00 \%$ & \\
\hline \multicolumn{8}{|l|}{ DAl severity and treatment need } \\
\hline $\begin{array}{l}\text { Normal or minor malocclusion-no treatment need } \\
\text { or slight need }\end{array}$ & 75 & $45.45 \%$ & 54 & $40.00 \%$ & 129 & $43.00 \%$ & \multirow[t]{4}{*}{0.238} \\
\hline Definite malocclusion-treatment selective & 50 & $30.30 \%$ & 42 & $31.11 \%$ & 92 & $30.67 \%$ & \\
\hline Severe malocclusion-treatment highly desirable & 25 & $15.15 \%$ & 20 & $14.81 \%$ & 45 & $15.00 \%$ & \\
\hline $\begin{array}{l}\text { Very severe (handicapping) malocclusion-treatment } \\
\text { mandatory }\end{array}$ & 15 & $9.09 \%$ & 19 & $14.07 \%$ & 34 & $11.33 \%$ & \\
\hline \multicolumn{8}{|l|}{ ICON treatment need } \\
\hline No & 108 & $65.45 \%$ & 89 & $65.93 \%$ & 197 & $65.67 \%$ & \multirow[t]{2}{*}{0.932} \\
\hline Yes & 57 & $34.55 \%$ & 46 & $34.07 \%$ & 103 & $34.33 \%$ & \\
\hline \multicolumn{8}{|l|}{ ICON complexity } \\
\hline Easy & 47 & $28.48 \%$ & 42 & $31.11 \%$ & 89 & $29.67 \%$ & \multirow[t]{5}{*}{0.858} \\
\hline Mild & 84 & $50.91 \%$ & 63 & $46.67 \%$ & 147 & $49.00 \%$ & \\
\hline Moderate & 14 & $8.48 \%$ & 15 & $11.11 \%$ & 29 & $9.67 \%$ & \\
\hline Difficult & 14 & $8.48 \%$ & 8 & $5.93 \%$ & 22 & $7.33 \%$ & \\
\hline Very difficult & 6 & $3.64 \%$ & 7 & $5.19 \%$ & 13 & $4.33 \%$ & \\
\hline \multicolumn{8}{|l|}{ PAR } \\
\hline Almost ideal occlusion & 41 & $24.85 \%$ & 30 & $22.22 \%$ & 71 & $23.67 \%$ & \multirow[t]{3}{*}{0.833} \\
\hline Acceptable occlusion & 48 & $29.09 \%$ & 43 & $31.85 \%$ & 91 & $30.33 \%$ & \\
\hline Malocclusion & 76 & $46.06 \%$ & 62 & $45.93 \%$ & 138 & $46.00 \%$ & \\
\hline \multicolumn{8}{|l|}{ Periodontal status } \\
\hline CPI score $=0$ & 10 & $6.06 \%$ & 6 & $4.44 \%$ & 16 & $5.33 \%$ & \multirow[t]{2}{*}{0.536} \\
\hline CPI score $>0$ & 155 & $93.94 \%$ & 129 & $95.56 \%$ & 284 & $94.67 \%$ & \\
\hline CPI score $<2$ & 14 & $8.48 \%$ & 7 & $5.19 \%$ & 21 & $7.00 \%$ & \multirow[t]{2}{*}{0.266} \\
\hline $\mathrm{CPI}$ score $>=2$ & 151 & $91.52 \%$ & 128 & $94.81 \%$ & 279 & $93.00 \%$ & \\
\hline \multicolumn{8}{|l|}{ Caries experience } \\
\hline$<\mathrm{SiC}$ Index value & 135 & $81.82 \%$ & 122 & $90.37 \%$ & 257 & $85.67 \%$ & \multirow[t]{2}{*}{$0.036^{*}$} \\
\hline$>=\mathrm{SiC}$ Index value & 30 & $18.18 \%$ & 13 & $9.63 \%$ & 43 & $14.33 \%$ & \\
\hline $\mathrm{DMFT}=0$ & 61 & $36.97 \%$ & 62 & $45.93 \%$ & 123 & $41.00 \%$ & \multirow[t]{2}{*}{0.117} \\
\hline DMFT>0 & 104 & $63.03 \%$ & 73 & $54.07 \%$ & 177 & $59.00 \%$ & \\
\hline \multirow[t]{2}{*}{ DMFT } & & Mean (SD) & & Mean (SD) & & Mean (SD) & \\
\hline & 165 & $2.28(2.603)$ & 135 & 1.48 (1.977) & 300 & $1.92(2.373)$ & $0.003^{* *}$ \\
\hline
\end{tabular}

P: comparison for DMFT used the independent samples t test; others used the Mann-Whitney U test $\mathrm{SiC}$ Index: Significant Caries Index; SiC index value (SD) was 4.72 (2.021) 


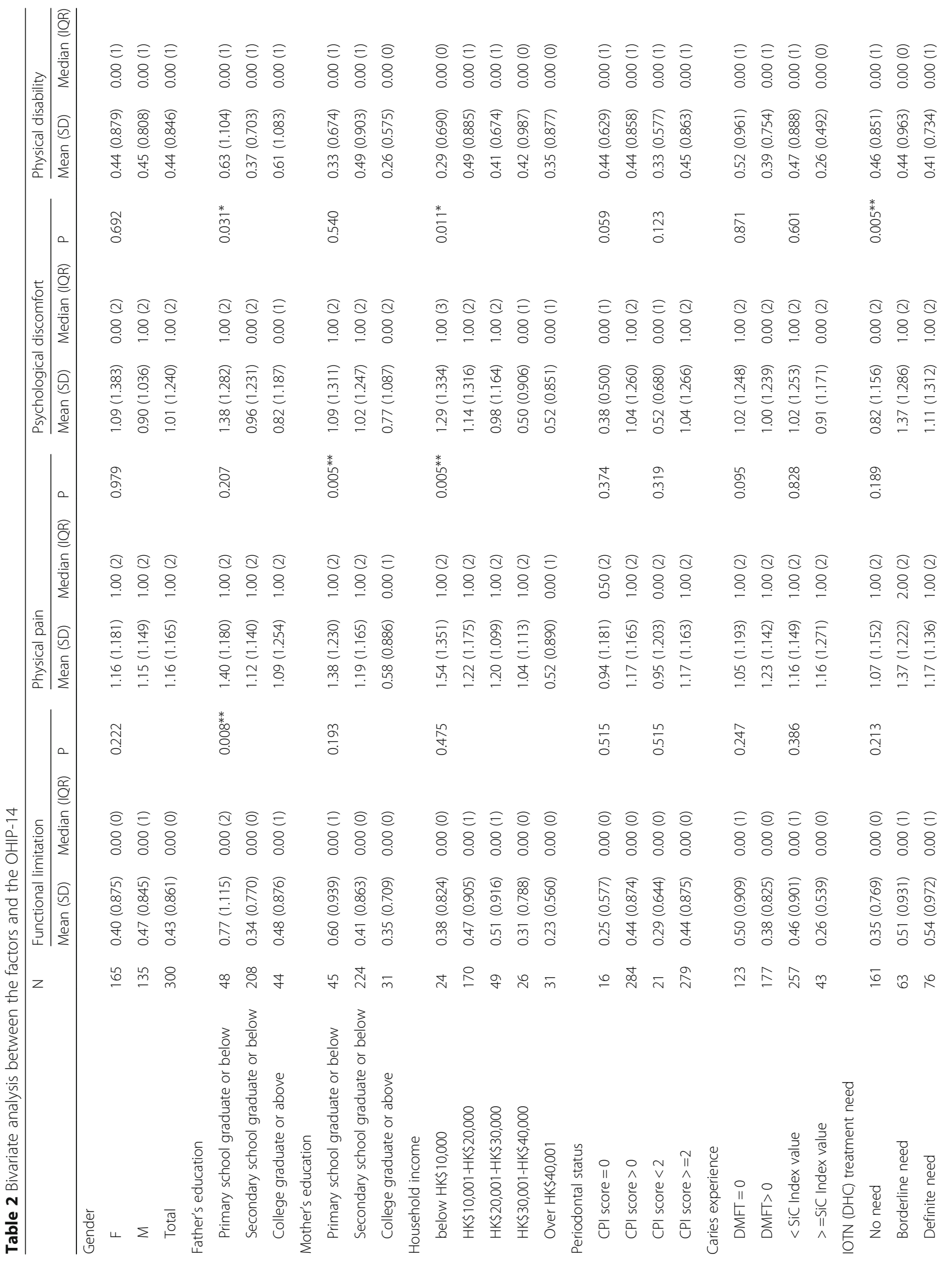




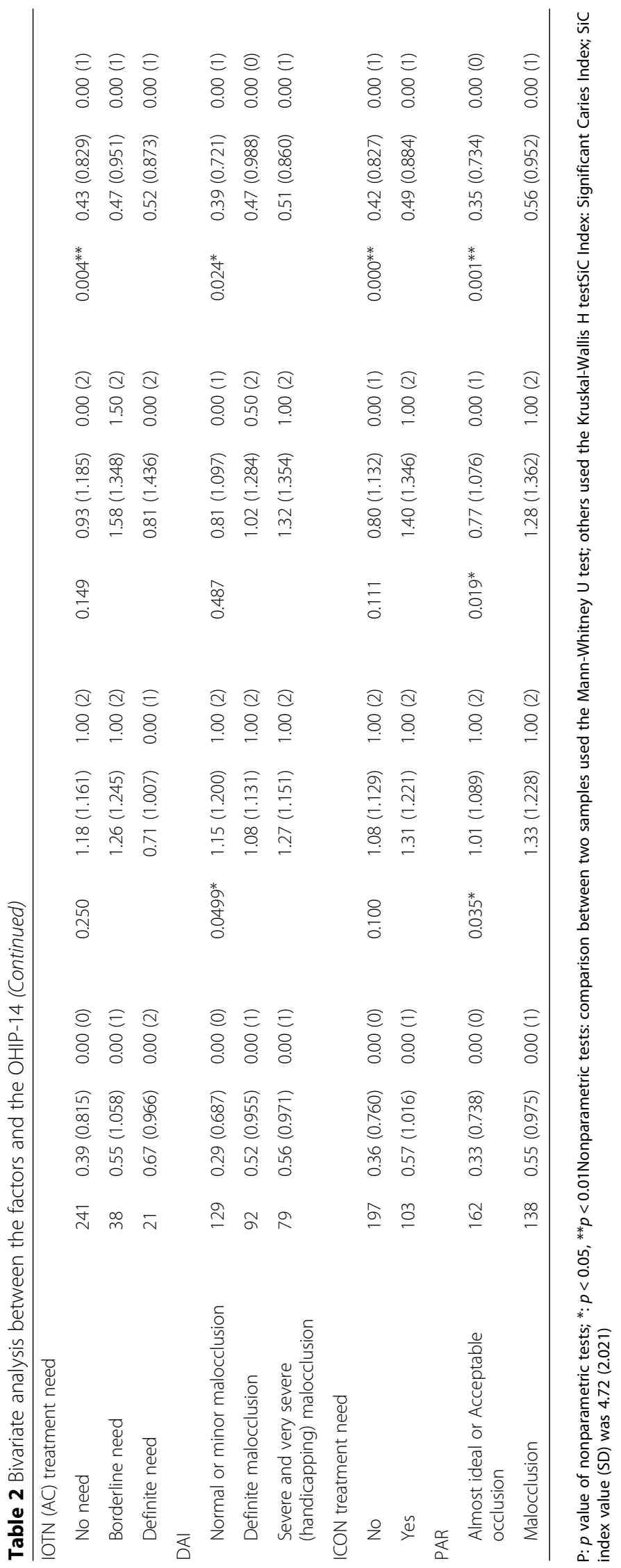




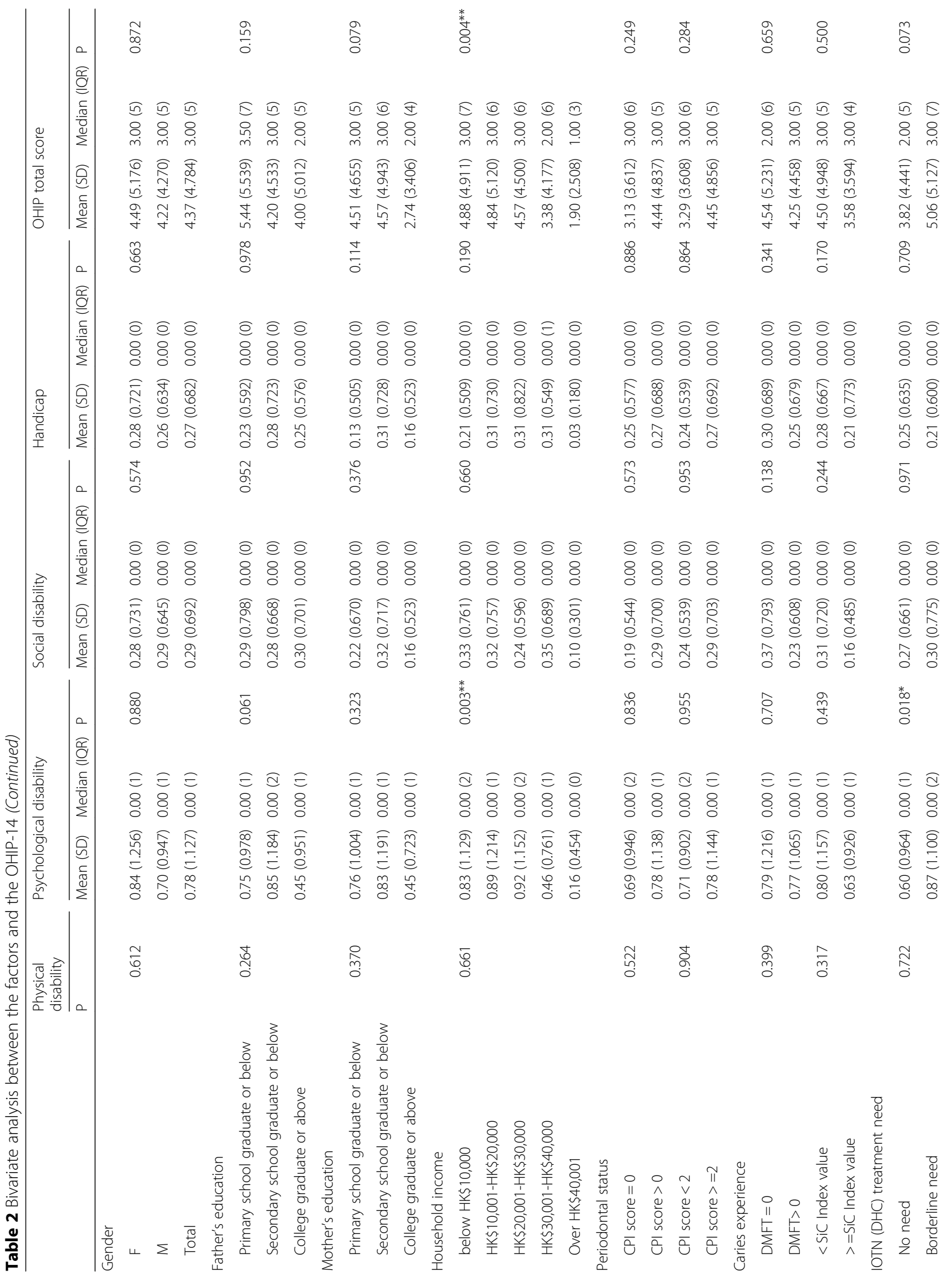




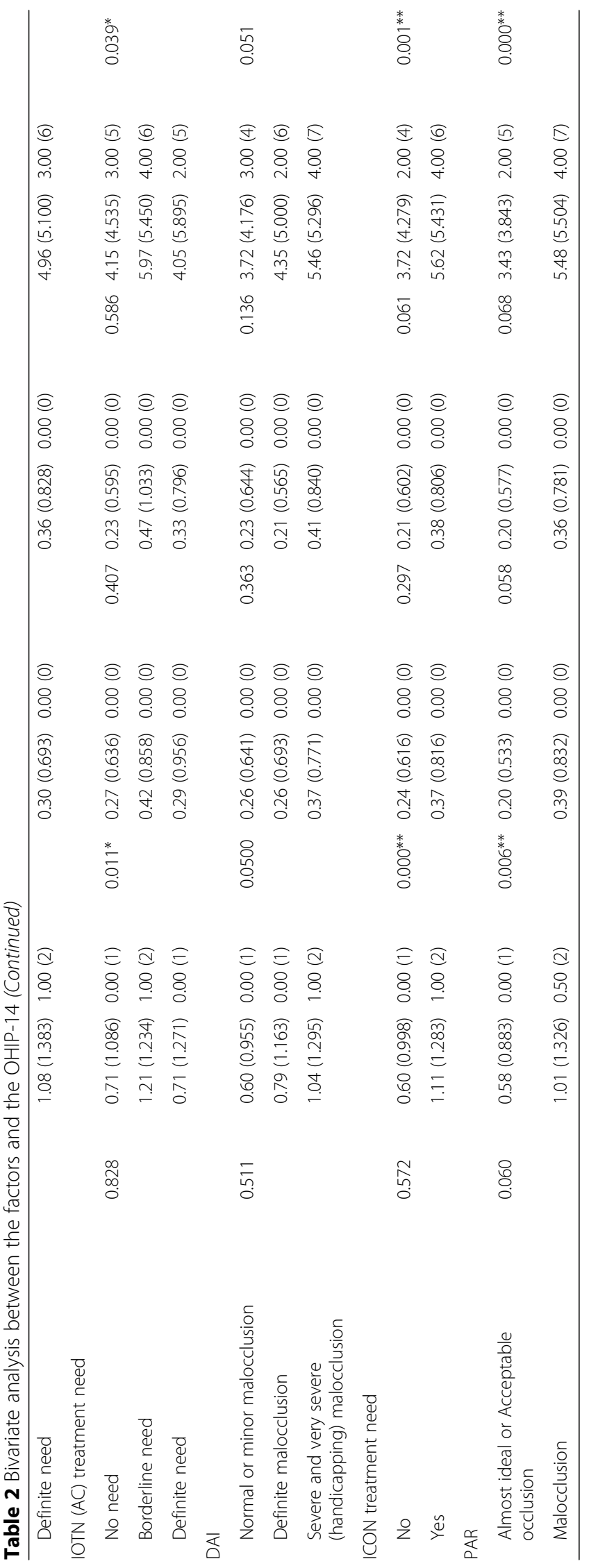




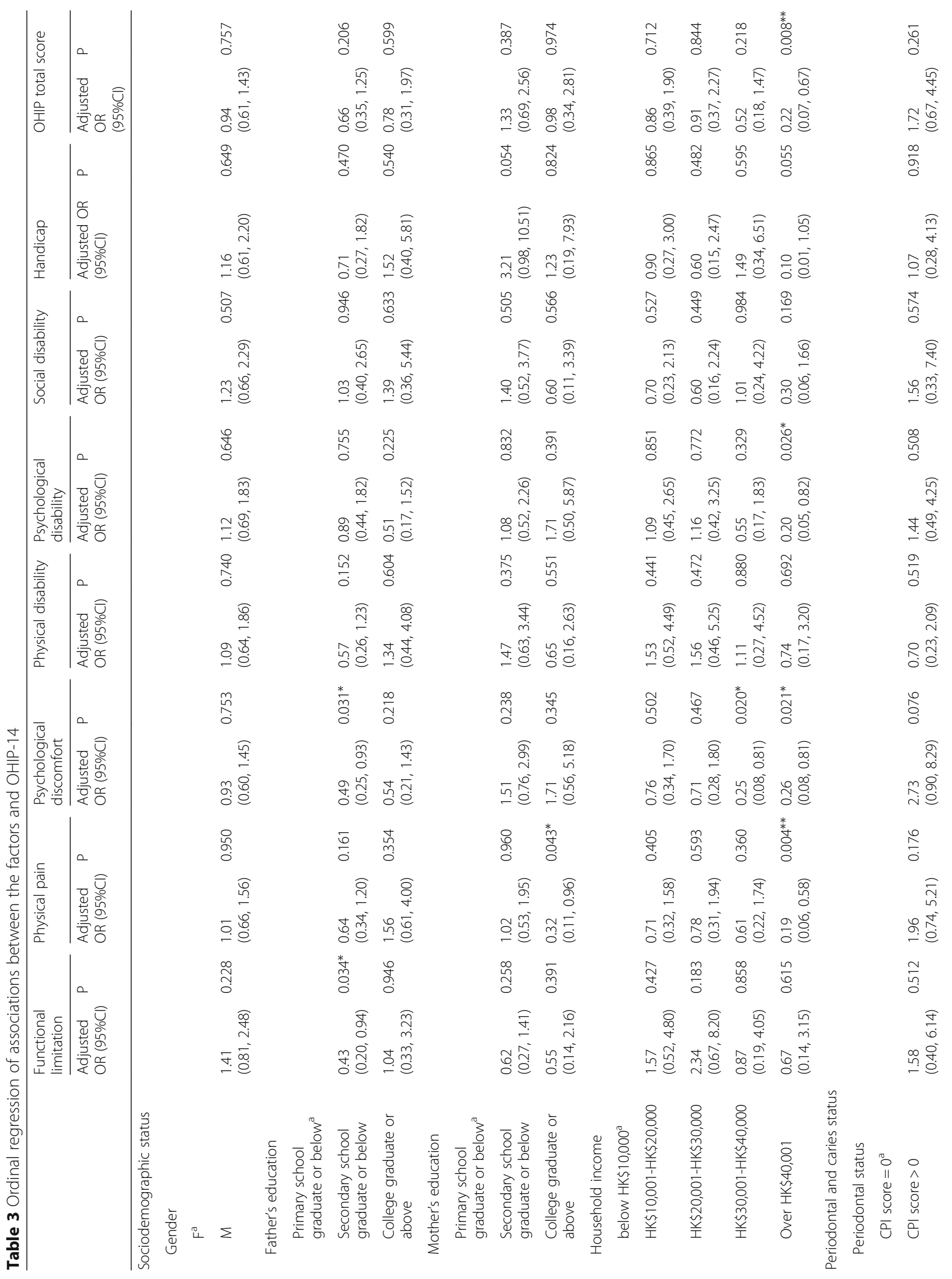




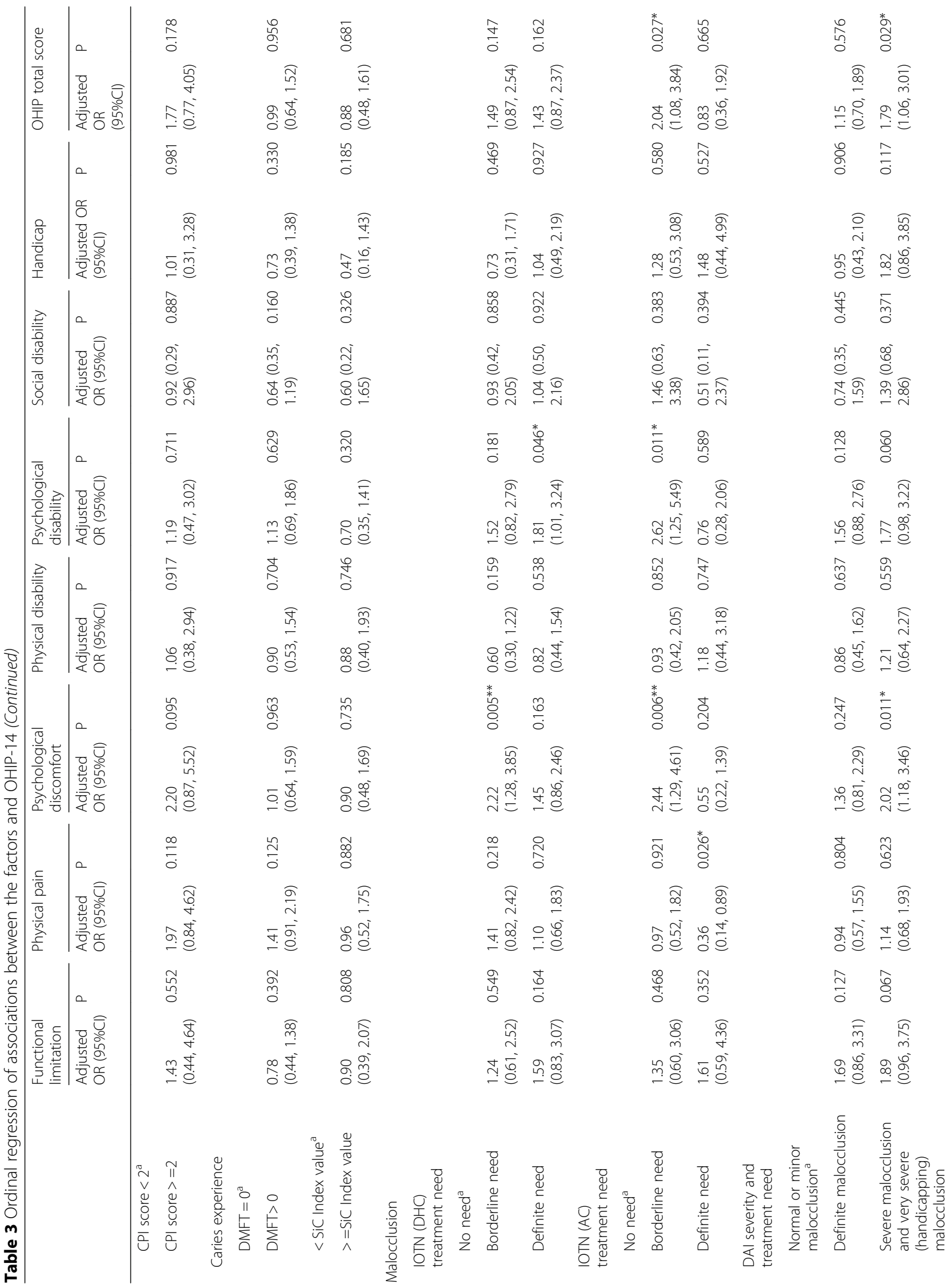




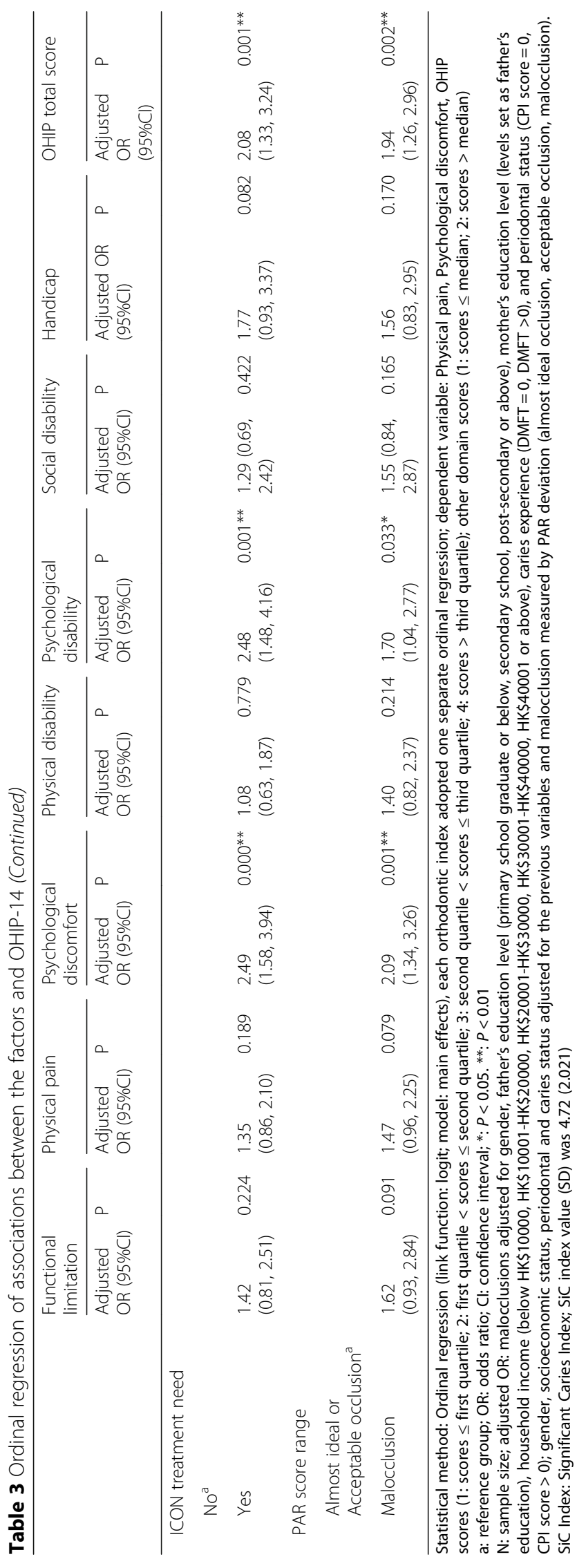


with healthy conditions. However, statistical results showed that periodontal status, as well as caries, had no effect on any subscale of OHIP-14. When malocclusion was classified into two groups by ICON and PAR, in all subscales of OHIP-14, subjects with malocclusion had a higher score than those without malocclusion. Nevertheless, not all subscales presented a significant result. The subscales of psychological discomfort and psychological disability were the most detected subscales: all indices showed a significant result in these two subscales. Among the used indices, PAR detected the most significant results.

The results of ordinal regression were almost the same with bivariate analysis (Table 3). Gender showed no effect on any subscale of OHIP-14. As for family ecosocial factors, household income showed the most effect on OHRQoL. The affected subscales were physical pain, psychological discomfort, psychological disability, and the total OHIP score. In these subscales, higher household incomes were associated with lower likelihoods of having worse OHRQoL; however, statistical results showed that only the last one or two groups with the highest incomes had significant effects on OHRQoL. Take the subscale of psychological discomfort for example. When compared with the first group, the last two groups had lower likelihoods of having problems in this subscale (adjusted OR $=0.25$ and 0.26 , respectively). Parents' education showed less effect on OHRQoL than household income did. Both father's and mother's education showed some positive effects, with father's education on functional limitation and psychological discomfort, and mother's education on physical pain.

Periodontal status and caries did not show any effect on subjects' OHRQoL after adjusting the effects of other factors. As for malocclusion, when classified into 2 groups by PAR or ICON, subjects with malocclusion had a higher likelihood of having a worse experience in all subscales of OHIP-14. Nevertheless, significant results were almost only shown in the subscales of psychological discomfort and psychological disability. It was also noticed that only the severe levels of malocclusion had an effect on OHRQoL. For example, when malocclusion was classified by DAI, there was no difference between the "definite malocclusion" group and the "normal or minor malocclusion" group, but the "severe and very severe malocclusion" group was associated with 1.79 times the likelihood of having a worse experience in the total OHIP when compared with the "normal or minor malocclusion" group $(p=0.029$, Table 3$)$.

\section{Discussion}

This study is part of a longitudinal study that followed subjects from age 12 to 18 . When comparing the results of this study with those at age 12 and age 15, sociodemographic factors showed an inconsistent effect on OHRQoL [27, 28]. First, gender was an influence factor of OHRQoL at both ages 12 and 15; while it was no longer an influence factor at age 18. Second, among family ecosocial factors, mother's education had the most effect on children's OHRQoL at age 12; whereas it was household income that had the most effect at age 18 , although it had little effect at ages 12 and 15 . Third, father's education had a negative effect on children's OHRQoL at age 12 but a positive effect at age 18. These results suggest that subjects of different age could have different experiences on the same condition, which support the hypothesis that quality of life is a "dynamic construct" that is likely to change overtime [2].

Gender showed no effect on OHRQoL in this study. Similarly, four studies from India, Korea, Saudi Arabia and Malaysia respectively included subjects aged between 18 to 22,18 to 32,21 to 25 , and 15 to 25 years; their results also showed that gender had little effect on OHRQoL [8-11]. Among family factors, household income presented the most effect on subjects' OHRQoL. A study assessed socioeconomic inequalities on OHRQoL in 8765 adults aged 21 years and over in England, Wales and Northern Ireland; the result also showed that probabilities of poor oral health and bad oral impacts were significantly higher for participants in lower income quintiles than those in the highest income level [29].

Unhealthy periodontal conditions were more prevalent than caries in all three surveys; and the prevalence of unhealthy periodontal conditions was increased slightly across the three surveys. However, the influence of periodontal status on OHRQoL was inconsistent as well: at age 12 and 15, periodontal status showed an effect on OHRQoL; while at age 18, it showed no effect on OHRQoL. A recent study from Brazil also reported an inconsistent impact of periodontal conditions on OHRQoL: the presence of bleeding had an impact on the domains of EWB and SWB of $\mathrm{CPQ}_{11-14}$ in 286 schoolchildren at age 12 [30]; however, when 170 children were followed from age 12 to 15 , the presence of bleeding had no impact on CPQ scores [31].

At age 12, no difference of caries was found between females and males; at age 15, the prevalence of caries was higher in females than in males; while at age 18, females had more severe caries than males did. Nevertheless, caries showed little effect on OHRQoL in all three surveys. This result may not be applied to other geographical regions. For example, a study from Japan investigated a group of university students and reported that caries was directly associated with OHRQoL [6]. Hong Kong has mature preventive and treatment conditions for caries, where untreated caries is not very prevalent; hence the symptoms of caries do not harm 
subjects' OHRQoL significantly. This result also indicates that although DMFT and $\mathrm{SiC}$ index are the common indices for caries assessment, other indices that could differentiate active caries from well-treated caries should be more helpful to determine the effect of caries on OHRQoL. For example, some studies recommended that one of such indices is International Caries Detection and Assessment System (ICDAS), which could discriminate between incipient lesions and lesions encompassing larger portions of the tooth [32, 33].

The effect of malocclusion on OHRQoL was detected across the three surveys of this study. Our systematic review showed that up to February 18, 2016, there were 13 studies testing the impact of untreated malocclusion on OHIP scores [34]. No matter which orthodontic indices were used, most of them reported that untreated malocclusion had an impact on OHIP scores; only 2 studies showed negative results [35, 36]. All subscales of OHIP questionnaire could be affected and the most reported subscale was psychological discomfort. This result was supported by this study: malocclusion could affect OHIP-14 scores; the most detected subscales were psychological discomfort and psychological disability.

Physical pain, psychological discomfort and psychological disability were the most affected subscales in this study; whereas handicap was a subscale that was not affected at all. In OHIP-14, the subscales of physical pain, psychological discomfort and disability demonstrate subjects may have painful aching and uncomfortable eating; they may be self-conscious, unsatisfied, or embarrassed because of their teeth. While the subscale of handicap demonstrates subjects may be unable to function or work because of their teeth. Therefore, the influence factors like household income and malocclusion could affect subjects' physical and psychological status. However, these effects were not profound enough to hazard their daily lives.

Although the population-based sample used in this study waived the bias of the convenient samples selected from dental clinics, the disadvantages of this study cannot be overlooked. First, this is only a cross-sectional analysis; further longitudinal analysis of this research should provide more helpful evidence. Second, this study was based on a sample selected from Hong Kong. Our systematic review showed that different regions could present different results of OHRQoL [34]. Therefore, when comparing this study with other studies, the differences of national, geographical, cultural, and economical situations need to be considered.

\section{Conclusion}

The influence factors of OHRQoL were studied in a representative sample of 18 -year-old subjects. Females had more severe caries than males did; however, gender was not a significant influence factor of OHRQoL. Among family ecosocial factors, household income affected subjects' OHRQoL most, while parents' education only had some positive effects on subscales of functional limitation, physical pain and psychological discomfort. Caries and unhealthy periodontal conditions had no effect on OHRQoL; while malocclusion had a negative effect on OHRQoL. The influence factors mainly affected the subscales of physical pain, psychological discomfort and psychological disability.

\section{Abbreviations}

AC: Aesthetic component; CPI: Community Periodontal Index; DAl: Dental aesthetic index; DHC: Dental health component; DMFT: Decayed, Missing and Filled Teeth; ICON: Index of complexity, outcome and need; IOTN: Index of orthodontic treatment need; OHIP: Oral health impact profile;

OHRQoL: Oral health-related quality of life; OR: Odds ratio; PAR: Peer assessment rating; SD: Standard deviation; SE: Standard error; SiC index: Significant caries index; WHO: World Health Organization

\section{Acknowledgements}

The work described in this paper was fully supported by a grant from the Research Grants Council of the Hong Kong Special Administrative Region, China (Project No. 17115916).

\section{Funding}

The Research Grants Council of the Hong Kong Special Administrative Region, China.

\section{Availability of data and materials}

The datasets used and/or analyzed during the current study are available from the corresponding author on reasonable request.

\section{Authors' contributions}

LS analyzed the data and prepared the manuscript. HMW contributed to the study design, data analysis and manuscript preparation, and acted as the corresponding author. CPM contributed to the study design and the manuscript preparation. All authors read and approved the final manuscript.

\section{Ethics approval and consent to participate}

The ethical approval of this study was granted by the Institutional Review Board of the University of Hong Kong/Hospital Authority Hong Kong West Cluster (UW 09-453). A written consent from parents/primary caregivers and a verbal consent from students were obtained from all participants.

\section{Consent for publication}

Not applicable.

\section{Competing interests}

The authors declare that they have no competing interests.

\section{Publisher's Note}

Springer Nature remains neutral with regard to jurisdictional claims in published maps and institutional affiliations.

\section{Author details}

${ }^{1}$ Paediatric Dentistry and Orthodontics, Faculty of Dentistry, The University of Hong Kong, 2/F, Prince Philip Dental Hospital, 34 Hospital Road, Sai Ying Pum, Hong Kong. ${ }^{2}$ Periodontology and Public Health, Faculty of Dentistry, The University of Hong Kong, Sai Ying Pum, Hong Kong.

Received: 18 April 2018 Accepted: 6 September 2018 Published online: 17 September 2018

\section{References}

1. Bennadi D, Reddy C. Oral health related quality of life. J Int Soc Prev Community Dent. 2013;3:1-6. 
2. Allison PJ, Locker D, Feine JS. Quality of life: a dynamic construct. Soc Sci Med. 1997:45:221-30.

3. Christie D, Viner R. Adolescent development. BMJ Br Med J. 2005;330:301.

4. Steinberg L, Morris AS. Adolescent development. Annu Rev Psychol. 2001; 52:83-110.

5. Maier HW. Adolescenthood. Soc Casework. 1965:46:3-9.

6. Yamane-Takeuchi M, Ekuni D, Mizutani S, Kataoka K, Taniguchi-Tabata A, Azuma T, Furuta M, Tomofuji T, Iwasaki Y, Morita M. Associations among oral health-related quality of life, subjective symptoms, clinical status, and self-rated oral health in Japanese university students: a cross-sectional study. BMC Oral Health. 2016;16:127.

7. Chen M, Feng Z-C, Liu X, Li Z-M, Cai B, Wang D-W. Impact of malocclusion on oral health-related quality of life in young adults. Angle Orthod. 2015;85:986-91.

8. Jay P, Goje SK, Narayan K, Riddhi P, Chinmay D, Aakash S. Impact of orthodontic treatment needs on Oral health-related quality of life among the early adults: a questionnaire study. J Int Oral Health. 2016;8:1095-110.

9. Masood Y, Masood M, Zainul NNB, Araby NBAA, Hussain SF, Newton T. Impact of malocclusion on oral health related quality of life in young people. Health Qual Life Outcomes. 2013;11:25.

10. Choi S-H, Kim B-I, Cha J-Y, Hwang C-J. Impact of malocclusion and common oral diseases on oral health-related quality of life in young adults. Am J Orthod Dentofac Orthop. 2015;147:587-95.

11. Hassan AH, Amin HE-S. Association of orthodontic treatment needs and oral health-related quality of life in young adults. Am J Orthod Dentofac Orthop. 2010;137:42-7

12. Slade GD. Derivation and validation of a short-form oral health impact profile. Community Dent Oral Epidemiol. 1997;25:284-90.

13. WHO. Oral health surveys: basic methods. ed 4 ed. Geneva: World Health Organization; 1997.

14. Bratthall D. Introducing the significant caries index together with a proposal for a new global oral health goal for 12-year-olds. Int Dent J. 2000;50:378-84.

15. Brook PH, Shaw WC. The development of an index of orthodontic treatment priority. Eur J Orthod. 1989;11:309-20.

16. Shaw W, Richmond S, O'Brien K. The use of occlusal indices: a European perspective. Am J Orthod Dentofac Orthop. 1995;107:1-10.

17. Richmond S, Shaw W, O'brien K, Buchanan I, Jones R, Stephens C, Roberts C, Andrews M. The development of the PAR index (peer assessment rating): reliability and validity. Eur J Orthod. 1992;14:125-39.

18. Jenny J, Cons NC. Establishing malocclusion severity levels on the dental aesthetic index (DAl) scale. Aust Dent J. 1996:41:43-6.

19. Daniels C, Richmond S. The development of the index of complexity, outcome and need (ICON). J Orthod. 2000;27:149-62.

20. Cons NC, Kohout FJ, Jenny J. DAl--the dental aesthetic index. lowa City: College of Dentistry, University of lowa; 1986.

21. Lunn H, Richmond S, Mitropoulos C. The use of the index of orthodontic treatment need (IOTN) as a public health tool: a pilot study. Community Dent Health. 1993;10:111-21.

22. Richmond S. An introduction to occlusal indices. Manchester, UK: Victoria University of Manchester: Mandent Press; 1992

23. Schooling CM, Hui LL, Ho LM, Lam T-H, Leung GM. Cohort profile:'children of 1997': a Hong Kong Chinese birth cohort. Int J Epidemiol. 2011:41:611-20.

24. Zhang M. Ph. D. Thesis: changes in children's oral health related quality of life following orthodontic treatment. Hong Kong: The University of Hong Kong; 2007.

25. Eldridge SM, Ashby D, Kerry S. Sample size for cluster randomized trials: effect of coefficient of variation of cluster size and analysis method. Int J Epidemiol. 2006;35:1292-300.

26. Killip S, Mahfoud Z, Pearce K. What is an intracluster correlation coefficient? Crucial concepts for primary care researchers. Ann Fam Med. 2004;2:204-8.

27. Sun $\mathrm{L}$, Wong $H M$, McGrath CP. The factors that influence the oral healthrelated quality of life in 12-year-old children: baseline study of a longitudinal research. Health Qual Life Outcomes. 2017;15:155.

28. Sun L, Wong HM, McGrath CP. The factors that influence oral health-related quality of life in 15-year-old children. Health Qual Life Outcomes. 2018;16:19.

29. Guarnizo-Herreño C, Watt RG, Fuller E, Steele JG, Shen J, Morris S, Wildman J, Tsakos G. Socioeconomic position and subjective oral health: findings for the adult population in England, Wales and Northern Ireland. BMC Public Health. 2014;14:827.

30. de Paula JS, Leite ICG, de Almeida AB, Ambrosano GMB, Mialhe FL. The impact of socioenvironmental characteristics on domains of oral health-related quality of life in Brazilian schoolchildren. BMC Oral Health. 2013;13:10.
31. Paula JS, Cruz JND, Ramires TG, Ortega EMM, Mialhe FL. Longitudinal impact of clinical and socioenvironmental variables on oral health-related quality of life in adolescents. Braz Oral Res. 2017;31:e70.

32. Ismail A, Sohn W, Tellez M, Amaya A, Sen A, Hasson H, Pitts N. The international caries detection and assessment system (ICDAS): an integrated system for measuring dental caries. Community Dent Oral Epidemiol. 2007; 35:170-8

33. García-Pérez Á, Irigoyen-Camacho ME, Borges-Yáñez SA, Zepeda-Zepeda MA, Bolona-Gallardo I, Maupomé G. Impact of caries and dental fluorosis on oral health-related quality of life: a cross-sectional study in schoolchildren receiving water naturally fluoridated at above-optimal levels. Clin Oral Investig. 2017;21(9):2771-80.

34. Sun L, Wong HM, McGrath CP. The relationship between the severity of malocclusion and Oral health related quality of life: a systematic review and meta-analysis. Oral Health Prev Dent. 2017:15:503-17.

35. Oliveira DC, Ferreira FM, de Almeida Castro Morosini I, Torres-Pereira CC, Paiva SM, Fraiz FC. Impact of Oral health status on the Oral health-related quality of life of Brazilian male incarcerated adolescents. Oral Health Prev Dent. 2015;13:417-25.

36. Anosike AN, Sanu OO, Da CO. Malocclusion and its impact on quality of life of school children in Nigeria. West Afr J Med. 2010;29:417-24.

Ready to submit your research? Choose BMC and benefit from:

- fast, convenient online submission

- thorough peer review by experienced researchers in your field

- rapid publication on acceptance

- support for research data, including large and complex data types

- gold Open Access which fosters wider collaboration and increased citations

- maximum visibility for your research: over $100 \mathrm{M}$ website views per year

At $\mathrm{BMC}$, research is always in progress.

Learn more biomedcentral.com/submissions 